\title{
En prospektiv undersøkelse av sammenhengen mellom kosthold og kreft blant middelaldrende kvinner og menn i Norge 1977-1992 Prosjektbeskrivelse
}

\author{
Marit Bragelien Veierød \\ Seksjon for medisinsk statistikk, Universitetet i Oslo, Boks 1122 Blindern, 0317 Oslo \\ Telefon 22851432 Telefax $22851313 \quad$ E-mail: marit.veierod@basalmed.uio.no
}

\begin{abstract}
SAMMENDRAG
I USA er det anslått at 30\% av alle dødsfall som skyldes kreftsykdom kan tilskrives kosthold i voksen alder (inkludert kostholdets betydning for overvekt). ${ }^{4}$ Fra Statens helseundersøkelser sine hjertekarundersøkelser i Finnmark, Sogn og Fjordane og Oppland i 1977-83, foreligger data om kosthold for vel 50000 menn og kvinner i alderen 16-56 år. Kopling mot Kreftregisteret og Statistisk sentralbyrå gir oss mulighet til å se nærmere på sammenhengen mellom kosthold og risiko for kreft $\mathrm{i}$ en kohortstudie med komplett oppfølging med hensyn på forekomst av kreft, død og emigrasjon. I henhold til kontrakten om bruk av den koplete datafila, studerer vi i dette prosjektet sammenhengen mellom kosthold og risiko for kreft i magesekk, bukspyttkjertel, livmorhals, prostata, lunger og hud (malignt melanom). Den statistiske styrken i epidemilogiske studier som denne, samt hvilken betydning målefeil i kostholdsvariablene har for risikoestimatene og den statistiske styrken, blir også vurdert. Denne artikkelen gir en nærmere presentasjon av prosjektet og de metodene som benyttes.
\end{abstract}

Veierød MB. A prospective study of diet and cancer in middle-aged women and men in Norway 1977-1992. Project description. Nor J Epidemiol 1997; 7 (2): 201-204.

\section{ENGLISH SUMMARY}

The relationship beteen dietary habits and the incidence of cancer is studied in 50,000 Norwegian men and women aged 16-56 years attending a Norwegian health screening in 1977-83. Linkage to the Cancer Registry of Norway and the Central Bureau of Statistics of Norway ensure a complete follow-up until 31 December 1992. The cancer sites included in this project are the stomach, pancreas, cervix, prostate, lung and malignant melanoma. Diet was recorded on a semi-quantitative food-frequency questionnaire at the time of screening, and intake of energy and fats are estimated. The attenuation of effect estimates due to measurement errors in the dietary variables will be investigated, as well as the power of the study. The project is not finished yet, and this paper gives a description of the project and the methods of statistical analysis. The first results were published in the International Journal of Cancer earlier this year. ${ }^{1}$

\section{INNLEDNING}

Dette er et doktorgradsprosjekt ved Seksjon for medisinsk statistikk, Universitetet i Oslo (UiO), finansiert av Den Norske Kreftforening og Den Norske Lægeforening. Veilederkomiteen består av professor Christian Drevon (Avdeling for kostholdsforskning, UiO), professor Petter Laake (Seksjon for medisinsk statistikk, UiO) og professor Dag S. Thelle (Seksjon for epidemiologisk forskning, UiO). I tillegg inngår avdelingsleder Steinar Tretli (Kreftregisteret) og forsk- ningssjef Aage Tverdal (Statens helseundersøkelser) i forskningsgruppen for prosjektet.

Prosjektet er nå godt $\mathrm{i}$ gang. I løpet av to års stipendperiode er sammenhengen mellom kosthold (spesielt inntak av fett og fettrike matvarer) og risiko for kreft $\mathrm{i}$ hud, lunger og prostata ferdig analysert. Resultatene vil bli publisert i internasjonale tidsskrifter og den første artikkelen, som omhandler kosthold og risiko for hudkreft, stod i International Journal of Cancer tidligere i år. ${ }^{1}$ Nedenfor følger en presentasjon av prosjektet. 


\section{BAKGRUNN}

Kosthold og levevaner står sentralt i studier av sykelighet og død av kreft. I 1981 ble det av Doll og Peto ${ }^{2}$ anslått at $35 \%$ av alle kreftsykdommer kan tilskrives kostholdet (variasjonsbredde 10-70\%). Dette estimatet, men med smalere variasjonsbredde (20-60\%), ble opprettholdt i en artikkel av Doll ${ }^{3}$ fra 1992. I den nylig publiserte amerikanske rapporten 'Harvard report on cancer prevention' ble det fastlått at de viktigste årsaksfaktorene til kreftsykdom er røyking, kosthold, overvekt og mangel på fysisk aktivitet. ${ }^{4}$ Det ble anlått at $30 \%$ av alle dødsfall $i$ USA som skyldes kreftsykdom kan tilskrives kosthold i voksen alder (inkludert kostholdets betydning for overvekt). De fleste kost/kreft hypotesene postulerer enten at en kostholdsfaktor opptrer som karsinogen eller cokarsinogen slik at for store mengder av faktoren øker kreftrisikoen, eller at en kostholdsfaktor virker beskyttende.

En av de best etablerte sammenhengene innen ernæringsepidemiologi er den beskyttende effekten som frukt og grønnsaker har på de fleste kreftformer. ${ }^{5}$ Hvilke næringsstoffer i frukt og grønnsaker som beskytter er fortsatt uavklart, spesielt etter at tre store intervensjonsstudier av $\beta$-karoten supplement ikke fant noen beskyttende effekt av $\beta$-karoten slik man hadde ventet. Ved siden av $\beta$-karoten, er bl.a. vitamin $\mathrm{C}$ og $\mathrm{E}$ foreslått pga. sine antioksiderende egenskaper. ${ }^{5}$

Høyt inntak av fett synes å gi økt risiko for kreft, og det er spesielt kreft i tykktarm, prostata, lunge og bryst som her har vært studert. ${ }^{5,6} \varnothing \mathrm{kt}$ risiko forbundet med høyt inntak av totalt fett, mettet fett og kolesterol er funnet i flere epidemiologiske studier av lungekreft ${ }^{7}$ og siden matvarer som meieriprodukter, kjøtt og egg er viktige kolesterol- og fettkilder, har også disse vært analysert med tanke på en eventuell sammenheng med risiko for lungekreft. ${ }^{8,9}$ Den kreftformen hvor de sterkeste sammenhengene med fett er funnet er prostatakreft, der flere studier viser økt risiko med økt inntak av animalsk fett. ${ }^{10}$ Det er imidlertid på bakgrunn av de studier som til nå foreligger, ikke mulig å trekke noen endelig konklusjon om en eventuell sammenheng mellom fettinntak og risiko for kreftsykdom.

Sammenhenger mellom inntak av næringsstoffer og kreft kan ikke uten videre tilskrives kostholdet, siden de kan være et resultat av forskjeller mellom individer med og uten kreft med hensyn på kroppsstørrelse, fysisk aktivitet og forbrenning. Dette er de tre faktorene som i størst grad bidrar til forskjeller i totalt energiinntak mellom individer, og det anbefales derfor å justere for totalt energiinntak i analyser av næringsstoffers sammenheng med risiko for kreft. ${ }^{11}$ Eksempelvis er inntak av fett sterkt korrelert til totalt energiinntak, og det er viktig å estimere effekten av fett uavhengig av totalt energiinntak. Mange publiserte studier er basert på begrenset informasjon om kosthold og kan derfor ikke beregne energi-justert fettinntak. Ser vi for eksempel på kreft i prostata som er den hyppigste kreftformen hos norske menn og utgjør $20 \%$ av de mannlige norske kreftdødsfallene, er det bare én av de hittil 8 utenlandske publiserte kohortstudiene som justerer for totalt energiinntak. ${ }^{12}$

Gjennomsnittlig inntak av næringsstoffer over tid kan variere fra person til person (variasjon mellom individer), men for en og samme person kan også daglig inntak variere pga. årstid, ukedag osv. (variasjon innen individ). Forutsetningen for å kunne påvise en eventuell assosiasjon mellom en kostfaktor og sykelighet eller død er at variasjonen innen individ er 'liten' og variasjonen mellom individ 'stor'. Målefeil i eksponeringsvariablene, uavhengig av sykdomsstatus, vil medføre en underestimering av en eventuell effekt. ${ }^{13}$ Dette oppstår fordi noe av variasjonen i det målte inntaket skyldes målefeil: den gruppen som er kategorisert med høyest inntak av en kostholdsvariabel vil inneholde et antall individer registrert med et feilaktig for høyt inntak, mens gruppen kategorisert med det laveste inntaket vil inneholde et antall individer med feilaktig for lavt inntak. Dette medfører at den sanne forskjellen mellom disse to gruppene vil bli mindre enn den i virkeligheten er, og effekten av kostholdsvariablen blir underestimert eller i verste fall oversett.

I forbindelse med Statens helseundersøkelser sine hjerte-karundersøkelser i Finnmark, Sogn og Fjordane og Oppland i 1977-83, ble vel 52000 undersøkte menn og kvinner spurt om kosthold. Ved hjelp av Kreftregisteret og Statistisk sentralbyrå foreligger også opplysninger om kreftsykdom, død og emigrasjon for de undersøkte. Dette relativt store datamaterialet med både høy deltager- og svarprosent, kostholdsopplysninger samlet inn før utbrudd av kreft og fullstendig oppfølging med hensyn på kreft, død og emigrasjon, gir oss mulighet til å se nærmere på sammenhengen mellom kosthold og risiko for kreft (Kreftregisterets rutiner sikrer bedre diagnoseregistrering enn i utenlandske studier).

\section{FORMÅL MED PROSJEKTET}

1. A identifisere mulige sammenhenger mellom kosthold og risiko for kreft i lunger, hud (malignt melanom), prostata, livmorhals, magesekk og bukspyttkjertel, samt risiko for kreftsykdom uansett lokalisasjon. Vi har også mulighet til å undersøke betydningen av kostvanene som risikofaktorer for kreftsykdom i forhold til total dødelighet.

2. A vurdere den statistiske styrken i epidemiologiske studier som denne, og hvilken betydning målefeil i kostholdsvariablene vil ha for risikoestimatene og den statistiske styrken.

\section{MATERIALE OG METODER}

\section{Studiepopulasjon}

I 1974-76 startet Statens helseundersøkelser sine hjerte-karundersøkelser av alle innbyggere $\mathrm{i}$ alderen 35-49 år og et tilfeldig utvalg i alderen 20-34 år i Finnmark, Sogn og Fjordane og Oppland. Annen gangs undersøkelse ble utført i 1977-83, og danner grunn- 
laget for denne prospektive studien. Denne gangen ble alle som fortsatt bodde i fylket invitert, sammen med et tilfeldig utvalg i alderen 20-39 år (16-39 i Sogn og Fjordane), og et spørreskjema om kosthold ble delt ut til de undersøkte. 71771 menn og kvinner ble innkalt til annen gangs undersøkelse og 63025 (88\%) deltok.

\section{Kostholdsskjemaet}

Kostholdsskjemaet, et såkalt selvadministrert matvarefrekvens-skjema, er utviklet ved Avdeling for kostholdsforskning (AKF) ved Universitetet i Oslo og består av 54 spørsmål. Det ble delt ut ved hjertekarundersøkelsen og returnert pr. post (purret en gang). Blant de undersøkte var det 26119 menn (82\%) og 25920 kvinner (83\%) som besvarte kostholdsskjemaet. Beskrivelse av spørreskjemaet og skjemaets reproduserbarhet og validitet finnes i publikasjoner fra AKF. ${ }^{14,15}$ Spørreskjemaet ble utformet spesielt med tanke på å kartlegge de vesentligste fettkildene i norsk kosthold, og Gaard et al. ${ }^{16}$ har utviklet en metode for beregning av totalt energiinntak og inntak av totalt fett, mettet fett, flerumettet fett, enumettet fett og kolesterol fra disse dataene. Konsum av melk, poteter, brød, pålegg (ost, syltetøy, kjøtt, salater), fett på brød, fett i matlaging, et bredt utvalg fisk og kjøttmåltider, kaker, egg, appelsiner, grøt, tran og vitaminpiller inngår $\mathrm{i}$ beregningene som kan utføres på $98 \%$ av de som besvarte spørreskjemaet.

\section{Identifikasjon av kreft, dod og emigrasjon}

Deltagerne fra andre gangs hjerte-karundersøkelse er fulgt opp til og med 31. desember 1992 med tanke på forekomst av kreft, død og emigrasjon. Krefttilfellene er identifisert ved kopling mot Kreftregisteret, mens informasjon om død og emigrasjon er hentet ved kopling til Statistisk sentralbyrå. 542 personer med kreftdiagnose før inklusjon i undersøkelsen blir ekskludert fra analysene. Vår studiepopulasjon består av totalt 51497 personer, der næringsinntak kan beregnes for 50757 personer. Antall krefttilfeller for de kreftformene som inngår i dette prosjektet er gitt i tabell 1.

\section{Statistiske metoder}

Poisson regresjonsanalyse blir anvendt for å analysere sammenhengen mellom kostholdsfaktorer og risiko for kreft. Personår beregnes fra hjerte-kar undersøkelsen og frem til tidspunktet for kreft, død, emigrasjon eller utgangen av oppfølgingstiden. Det blir justert for startalder, oppnådd alder, kjønn, røyking, fylke, body mass index, body surface area, fysisk aktivitet, utdanning o.1. avhengig av hvilken kreftform som analyseres.

Inntak av totalt fett, mettet fett, flerumettet fett, enumettet fett og kolesterol blir justert for totalt energiinntak ved regresjonsmetoden. ${ }^{11}$ Residualene fra en lineær regresjonsmodell med energiinntak som uavhengig variabel og absolutt næringsinntak som avhengig variabel, blir beregnet. Pr. definisjon vil næringsstoff-residualen være ukorrelert med totalt energiinntak. For å få intuitivt tolkbare verdier, blir forventet inntak av næringsstoffet for en person med gjennomsnittlig energiinntak lagt til residualene før de blir inkludert i den påfølgende analysen. Individene blir kategorisert i henhold til kvartiler/kvintiler av energi-justerte verdier av kolesterol og totalt og spesifikt fettinntak.

Betydningen av eventuelle målefeil i kostholdsvariablene blir analysert ved hjelp av simulering. Vi kan da vurdere hvilken innvirkning ulik grad av målefeil vil ha på de estimerte relative risikoene for kreft. Målefeilenes størrelse vil bli basert på de 24 og 48 timers intervjuene om kosthold (24/48 hour recall) som er foretatt på underutvalg av studiepopulasjonen. ${ }^{15,17,18}$ Det utvikles stadig metoder for å evaluere størrelsen på målefeil og inkludere dette $\mathrm{i}$ beregningen av estimater og i analyser av relasjoner mellom variable, f.eks. Rosner et al. ${ }^{19-21}$ og Plummer og Clayton. ${ }^{22,23}$

Statistisk styrke blir beregnet i Poisson regresjonsmodeller, og de aktuelle kovariatene for de enkelte kreftformene blir inkludert i modellene.

Tabell 1. Antall krefttilfeller blant 25708 menn og 25 049 kvinner med en gjennomsnittlig oppfølgingstid på 12 år (alder 16-56 ved undersøkelsen). Bare de kreftformene som inngår i dette prosjektet er med.

\begin{tabular}{lccc}
\hline & \multicolumn{3}{c}{ Antall krefttilfeller } \\
\cline { 2 - 4 } Lokalisasjon & Menn & Kvinner & Totalt \\
\hline Lunge & 127 & 49 & 176 \\
Malignt melanom & 47 & 61 & 108 \\
Prostata & 72 & - & 72 \\
Livmorhals & - & 68 & 68 \\
Magesekk & 65 & 41 & 106 \\
Bukspyttkjertel & 31 & 23 & 54 \\
\hline
\end{tabular}

\section{REFERANSER}

1. Veierød MB, Thelle DS, Laake P. Diet and risk of cutaneous malignant melanoma: a prospective study of 50,757 Norwegian men and women. Int J Cancer 1997; 71: 600-4.

2. Doll R, Peto R. The causes of cancer: quantitative estimates of avoidable risks of cancer in the United States today. J Natl Cancer Inst 1981; 66: 1191-308.

3. Doll R. The lessons of life: keynote address to the Nutrition and Cancer Conference. Cancer Res 1992; 52 (7 Suppl): 2024-9. 
4. Harvard Report on Cancer Prevention. Vol. 1: Causes of Human Cancer. Cancer Causes Control 1996; 7: $1-58$.

5. Willett WC. Diet and nutrition. In: Schottenfeld D, Fraumeni JF, Jr. Cancer epidemiology and prevention, 2nd ed. New York: Oxford University Press, 1996: 438-61.

6. Willett WC, Trichopoulos D. Nutrition and cancer: a summary of the evidence. Cancer Causes Control 1996; 7: 178-80.

7. Ziegler RG, Mayne ST, Swanson CA. Nutrition and lung cancer. Cancer Causes Control 1996; 7: 15777.

8. Mettlin CJ, Scoenfeld ER, Natarajan N. Patterns of milk consumption and risk of cancer. Nutr Cancer 1990; 13: 89-99.

9. Goodman MT, Hankin JH, Wilkens LR, Kolonel LN. High-fat foods and the risk of lung cancer. Epidemiology 1992; 3: 288-99.

10. Kolonel LN. Nutrition and prostate cancer. Cancer Causes Control 1996; 7: 83-94.

11. Willett W, Stampfer MJ. Total energy intake: implications for epidemiologic analyses. Am J Epidemiol 1986; 124: 17-27.

12. Giovannucci E, Rimm EB, Colditz GA, Stampfer MJ, Ascherio A, Chute CC, Willett WC. A prospective study of dietary fat and risk of prostate cancer. $J$ Natl Cancer Inst 1993; 85: 1571-79.

13. Rothman KJ. Modern epidemiology. Boston/Toronto: Little, Brown and Company, 1986: 84-9.

14. Løken EB, Solvoll K. The reproducibility of a self-administered diet questionnaire. Vår Føda 1987; 39 (1 Suppl): 33-7.

15. Solvoll K, Løken EB, Grønn M, Andersson E. Kosthold i Vestre Toten 1982. Resultater fra 24 h recall blant menn og kvinner 24-54 år. Avdeling for kostholdsforskning, Universitetet i Oslo, 1985: Tabellrapport nr. 2.

16. Gaard M, Tretli S, Løken EB. Dietary fat and the risk of breast cancer: a prospective study of 25,892 Norwegian women. Int J Cancer 1995; 63: 13-7.

17. Blaker B, Solvoll K, Lund-Larsen K. Kosthold i Vestre Toten 1987. Resultater fra $24 \mathrm{~h}$ recall blant menn og kvinner 30-59 år. Avdeling for kostholdsforskning, Universitetet i Oslo, 1988: Tabellrapport nr. 6 .

18. Solvoll K, Lund-Larsen K, Åmlid G. Kosthold i Vestre Toten 1987. Resultater fra 48 h recall blant menn og kvinner 30-59 år. Avdeling for kostholdsforskning, Universitetet i Oslo, 1991: Vedlegg til tabellrapport nr. 6.

19. Rosner B, Willett WC, Spiegelman D. Correction of logistic regression relative risk estimates and confidence intervals for systematic within-person measurement error. Stat Med 1989; 8: 1051-69.

20. Rosner B, Spiegelman D, Willett WC. Correction of logistic regression relative risk estimates and confidence intervals for measurement error: the case of multiple covariates measured with error. $\mathrm{Am} \mathrm{J}$ Epidemiol 1990; 132: 734-45.

21. Rosner B, Spiegelman D, Willett WC. Correction for logistic regression relative risk estimates and confidence intervals for random within-person measurement error. Am J Epidemiol 1992; 136: 1400 13.

22. Plummer M, Clayton D. Measurement error in dietary assessment: an investigation using covariance structure models. Part I. Stat Med 1993; 12: 925-35.

23. Plummer M, Clayton D. Measurement error in dietary assessment: an investigation using covariance structure models. Part II. Stat Med 1993; 12: 937-48. 